\title{
Dukungan Keluarga dalam Keikutsertaan KB pada Pasangan Usia Subur di Desa Argomulyo Sedayu Bantul Yogyakarta
}

\author{
Dwi Puspitasari', Siti Nurunniyah ${ }^{2}$ \\ 1,2 Sekolah Tinggi Ilmu Kesehatan Alma Ata Yogyakarta \\ Jalan Ringroad Barat Daya No 1 Tamantirto, Kasihan, Bantul, Yogyakarta
}

\begin{abstract}
Abstrak
Keikutsertaan KB di 6 Dusun yang terletak di Desa Argomulyo, Sedayu, Bantul yaitu Puluhan, Kemusuk Kidul, Karanglo, Pedes, Surobayan dan Kaliberot adalah 59,22\%. Persentase tersebut lebih rendah dibandingkan dengan angka rata-rata Kabupaten Bantul yang telah mencapai 81,40\%. Kemajuan program KB tidak bisa lepas dari adanya dukungan keluarga karena dukungan keluarga berkaitan erat dengan dorongan atau motivasi yang diberikan keluarga terhadap PUS untuk ikut berKB. Tujuan penelitian ini untuk mengetahui hubungan antara dukungan keluarga dengan keikutsertaan KB pada Pasangan Usia Subur (PUS) di Desa Argomulyo Sedayu Bantul Yogyakarta. Jenis penelitian ini adalah observasional, dengan pendekatan cross sectional. Populasi penelitian seluruh Pasangan Usia Subur (PUS) di 6 Dusun Desa Argomulyo yang berjumlah 916 responden. Teknik pengambilan sampel dilakukan secara total sampling. Instrumen penelitian yang digunakan berupa kuesioner. Pengujian hipotesis dengan uji Chi-Square $(\alpha=0,05)$. Dari hasil pengolahan data antara variabel dukungan keluarga dan keikutsertaan KB diperoleh $p=0,000$ OR=19,085; 95\% Cl 12,614 hingga 28,875 dan nilai koefisien kontingensi $=0,479$ sehingga ada hubungan positif yang signifikan antara dukungan keluarga dengan keikutsertaan KB. Simpulan bahwa terdapat hubungan positif antara dukungan keluarga dengan keikutsertaan KB pada Pasangan Usia Subur (PUS) di Desa Argomulyo Sedayu Bantul Yogyakarta.
\end{abstract}

Kata Kunci: dukungan keluarga, keikutsertaan KB

\section{Family Support in Family Planning Participation of Reproductive Age Couples in Argomulyo Village, Sedayu, Bantul, Yogyakarta}

\begin{abstract}
Family planning (FP) participation in 6 village located in Argomulyo, Sedayu, namely Puluhan, Kemusuk Kidul, Karanglo, Pedes, Surobayan and Kaliberot was 59.22\%. The percentage was lower than the average number of Bantul which reached $81.40 \%$. The progress of family planning programs can not be separated from their families since the family support is closely related to encouragement or motivation given to the reproductive age couples to participate in FP. The purpose of this study was to determine the relationship between family support and the participation of FP of reproductive age couples Argomulyo village Sedayu, Bantul, Yogyakarta. Study design used in this study was cross sectional. The total population of reproductive age couples in Argomulyo village were 916 respondents. The sampling technique was done by total sampling. The research instrument used in the form of questionnaires. Hypothesis testing with chi-square test $(\alpha=0.05)$. From the data analysis between family support and FP participation variables resulted on OR=19.09 $(95 \%$ $C l: 12.614-28.875)$ and contingency coefficient $=0.479$ and the FP participation. In conclusion, there was a positive relationship between family support with the FP participation on the spous of reproductive age couples in Argomulyo village, Sedayu, Bantul, Yogyakarta.
\end{abstract}

Keywords: family support, FP participation

Info Artikel:

Artikel dikirim pada 20 Oktober 2014

Artikel diterima pada 20 Oktober 2014 


\section{PENDAHULUAN}

Indonesia merupakan negara yang menempati posisi keempat dunia dengan jumlah penduduk saat ini yaitu sebesar 244,2 juta jiwa dengan laju pertumbuhan yang masih relatif tinggi. Laju Pertumbuhan Penduduk (LPP) meningkat dari data sensus tahun 2000 yaitu sebesar $1,40 \%$ menjadi 1,49\% pada tahun 2010 dan jumlah penduduk akan terus bertambah sesuai dengan LPP(1).

Dari peningkatan jumlah penduduk yang cukup pesat pemerintah melakukan berbagai program pembangunan Sumber Daya Manusia, salah satunya adalah dilaksanakan program Keluarga Berencana (KB). KB secara makro, berfungsi mengendalikan kelahiran, sedangkan dalam perspektif mikro bertujuan untuk membantu keluarga dan individu dalam mewujudkan hak-hak reproduksi, penyelenggaraan pelayanan, pengaturan, dan dukungan untuk membentuk keluarga kecil berkualitas(2).

Yogyakarta merupakan salah satu provinsi di Indonesia yang sudah mencapai tingkat fertilitas rendah yaitu sebesar $1,94 \%(3)$. Rendahnya tingkat fertilitas tersebut salah satunya dipengaruhi oleh tingginya keikutsertaan warga dalam ber-KB dan Pendewasaan Usia Perkawinan (PUP). Jumlah PUS di DIY sejumlah 554.531 pasangan, yang menjadi peserta KB aktif pada tahun 2013 sejumlah 444.718 pasangan atau sekitar $80,20 \%(4)$.

Berdasarkan hasil survei pada tahun 2013 di Kabupaten Bantul, Daerah Istimewa Yogyakarta, jumlah Pasangan Usia Subur sejumlah 152.793 pasangan, yang menjadi peserta KB aktif pada tahun 2013 sejumlah 124.372 pasangan atau sekitar $81,40 \%$. Pasangan usia subur yang bukan peserta KB ada sejumlah 28.421 pasangan(5).

Pasangan Usia Subur di Kecamatan Sedayu, Bantul berdasarkan data dari Badan Pusat Statistik tahun 2013 yang sudah aktif menggunakan alat kontrasepsi sejumlah 6.195 peserta dari 7.727 Pasangan Usia Subur yang ada (79,78\%)(3). Hasil studi pendahuluan yang dilakukan Januari 2014 pada 6 Dusun di Desa Argomulyo, Kecamatan Sedayu yang terdiri dari dusun Puluhan, Kemusuk, Karang Lo, Pedes, Kali Berot dan Surobayan, diketahui bahwa jumlah PUS adalah 900 pasangan dan persentase PUS yang mengikuti KB sebesar $59,22 \%$, sementara yang tidak ber-KB sekitar $40,8 \%$.

Jika dilihat dari persentase berdasarkan data di atas, akseptor KB di 6 Dusun di Desa Argomulyo masih rendah. Keikutsertaan KB pada PUS di pengaruhi oleh beberapa faktor, salah satu diantaranya adalah dukungan keluarga. Dukungan keluarga berkaitan erat dengan dorongan atau motivasi yang diberikan keluarga terhadap PUS untuk ikut ber-KB. Pasangan usia subur dengan keluarga yang memberikan dukungan akan menganggap bahwa dirinya dicintai dan diperhatikan. Hal tersebut dikarenakan dukungan keluarga dapat diartikan sebagai suatu bentuk sikap, kemauan, keikutsertaan dan kemampuan keluarga untuk memberikan bantuan kepada anggota keluarga yang membutuhkan baik dalam hal pemecahan masalah, pemberian keamanan dan peningkatan harga diri(6).

Penelitian menunjukkan bahwa ada hubungan yang signifikan antara dukungan suami dengan pemilihan alat kontrasepsi(7). Bila suami tidak mengizinkan atau tidak mendukung, maka hanya sedikit istri yang berani untuk tetap menggunakan alat kontrasepsi.

Hasil studi pendahuluan yang dilakukan di Puskesmas Sedayu I Bantul pada bulan April 2014 dengan metode wawancara dari 10 akseptor lama $\mathrm{KB}$, didapatkan hasil 6 orang $(60 \%)$ tidak mendapat dukungan keluarga untuk melakukan kunjungan ulang KB. Adanya fenomena ini, hal yang kemudian menjadi penting untuk diperhatikan adalah faktor-faktor yang terkait dengan partisipasi PUS dalam ber-KB salah satunya dukungan keluarga.

Penelitian ini bertujuan untuk mengetahui hubungan dukungan keluarga dengan keikutsertaan KB pada Pasangan Usia Subur (PUS) di Desa Argomulyo, Sedayu, Bantul, Yogyakarta Tahun 2014.

\section{BAHAN DAN METODE}

Tempat penelitian adalah di 6 Dusun yang terletak di Desa Argomulyo Sedayu Bantul yaitu Dusun Puluhan, Kemusuk Kidul, Karanglo, Pedes, Surobayan dan Kaliberot serta dilaksanakan dari tanggal 3-18 Juni 2014. Jenis penelitian ini adalah observasional, dengan pendekatan cross sectional. Populasi adalah seluruh pasangan usia subur (PUS) di 6 Dusun Desa Argomulyo yang berjumlah 916 responden. Sampel yang diperoleh sejumlah 907 respoden yang telah memenuhi kriteria inklusi dan eksklusi. Teknik pengambilan sampel dilakukan secara total sampling. Instrumen penelitian yang digunakan berupa kuesioner. Pengujian hipotesis dengan uji chi-square $(\alpha=0,05)$.

\section{HASIL DAN BAHASAN}

\section{Karakteristik Responden}

Tabel 1 menunjukkan persentase umur responden yang tertinggi terdapat pada kelompok umur 20-35 tahun yaitu sebesar $52,5 \%$, sementara yang terendah pada kelompok umur $<20$ tahun 
Tabel 1. Distribusi Frekuensi Karakteristik Pasangan Usia Subur (PUS) Berdasarkan Umur, Agama, Pendidikan, dan Pekerjaan di Desa Argomulyo Sedayu Bantul Yogyakarta Tahun 2014

\begin{tabular}{|c|c|c|c|c|}
\hline \multirow{2}{*}{ Karakteristik } & \multicolumn{2}{|c|}{ Istri } & \multicolumn{2}{|c|}{ Suami } \\
\hline & $f$ & $\%$ & $f$ & $\%$ \\
\hline \multicolumn{5}{|l|}{ Umur } \\
\hline$<20$ tahun & 4 & 0,4 & 1 & 0,1 \\
\hline 20-35 tahun & 476 & 52,5 & 383 & 42,2 \\
\hline$>35$ tahun & 427 & 47,1 & 523 & 57,7 \\
\hline \multicolumn{5}{|l|}{ Agama } \\
\hline Islam & 888 & 97,9 & 888 & 97,9 \\
\hline Kristen & 10 & 1,1 & 10 & 1,1 \\
\hline Budha & 0 & 0 & 0 & 0 \\
\hline Hindu & 0 & 0 & 0 & 0 \\
\hline Katholik & 9 & 1,0 & 9 & 1,0 \\
\hline Khonghucu & 0 & 0 & 0 & 0 \\
\hline \multicolumn{5}{|l|}{ Pendidikan } \\
\hline Tidak tamat SD & 9 & 1,0 & 10 & 1,1 \\
\hline Tamat SD/sederajat & 82 & 9,0 & 28 & 8,6 \\
\hline Tamat SMP/sederajat & 150 & 16,5 & 127 & 14,0 \\
\hline Tamat SMA/sederajat & 548 & 60,4 & 563 & 62,1 \\
\hline TamatDiploma/lebih tinggi & 118 & 13,0 & 129 & 14,2 \\
\hline \multicolumn{5}{|l|}{ Pekerjaan } \\
\hline Petani/Peternak/Nelayan & 12 & 1,3 & 20 & 2,2 \\
\hline Buruh/Buruhtani & 148 & 16,3 & 304 & 33,5 \\
\hline Karyawan Swasta & 165 & 18,2 & 327 & 36,1 \\
\hline PNS/TNI/POLRI & 25 & 2,8 & 46 & 5,1 \\
\hline Wiraswasta & 136 & 15,0 & 187 & 20,6 \\
\hline Tidak bekerja & 404 & 44,5 & 3 & 0,3 \\
\hline Lain-lain & 17 & 1,9 & 20 & 2,2 \\
\hline Jumlah & 907 & 100,0 & 907 & 100,0 \\
\hline
\end{tabular}

Sumber: Data Primer tahun 2014

yaitu sebesar $0,4 \%$. Hal ini berarti, bahwa mayoritas responden dalam masa produktif. Persentase agama yang dianut oleh mayoritas PUS adalah agama Islam, yaitu sebesar $97,9 \%$. Persentase pendidikan terakhir yang telah ditempuh oleh masing-masing responden yang tertinggi terdapat pada pendidikan tingkat SMA/sederajat, yaitu sebesar $60,4 \%$ pada istri dan $62,1 \%$ pada suami, sementara yang terendah pada pendidikan tidak tamat SD yaitu sebesar 1,0\% pada istri dan $1,1 \%$ pada suami. Untuk persentase pekerjaan suami yang tertinggi terdapat pada golongan pekerjaan karyawan swasta yaitu sebesar $36,1 \%$, sementara yang terendah terdapat pada golongan tidak bekerja yaitu sebesar $0,3 \%$. Untuk persentase pekerjaan istri yang tertinggi terdapat pada golongan tidak bekerja/IRT yaitu sebesar $44,5 \%$, sementara yang terendah terdapat pada golongan pekerjaan petani/peternak, nelayan yaitu sebesar $1,3 \%$.

\section{Dukungan Keluarga}

Tabel 2 menunjukkan persentase responden yang mendapat dukungan rendah dari keluarga untuk ikutserta dalam ber-KB yaitu sebesar $50,8 \%$,
Tabel 2. Distribusi Frekuensi Dukungan Keluarga pada PUS di Desa Argomulyo Sedayu Bantul Yogyakarta Tahun 2014

\begin{tabular}{lcc}
\hline Dukungan Keluarga & f & \% \\
\hline Tinggi & 446 & 49,2 \\
Rendah & 461 & 50,8 \\
Jumlah & 907 & 100,0 \\
\hline
\end{tabular}

Sumber: Data Primer tahun 2014

sementara persentase responden dengan dukungan keluarga yang tinggi yaitu sebesar $49,2 \%$. Dengan demikian, pasangan usia subur di Desa Argomulyo Sedayu Bantul Yogyakarta mayoritas mendapat dukungan rendah dari keluarga untuk ikut serta dalam KB.

\section{Keikutsertaan KB}

Tabel 3 menunjukkan persentase responden yang ikut serta dalam ber-KB yaitu sebesar $67,3 \%$, sementara persentase responden yang tidak ikut serta dalam ber-KB yaitu sebesar $32,7 \%$. Hal ini berarti, bahwa mayoritas pasangan usia subur (PUS) di Desa Argomulyo sudah ikut serta dalam program KB. 
Tabel 3. Distribusi Frekuensi Keikutsertaan KB pada PUS di Desa Argomulyo Sedayu Bantul Yogyakarta Tahun 2014

\begin{tabular}{ccc}
\hline Keikutsertaan KB & $\mathbf{f}$ & \% \\
\hline Ikut serta KB & 610 & 67,3 \\
Tidak Ikut serta KB & 297 & 32,7 \\
Jumlah & 907 & 100,0 \\
\hline
\end{tabular}

Sumber: Data Primer tahun 2014

\section{Analisis Bivariat}

Berdasarkan Tabel 4, menunjukkan persentase bahwa kelompok responden dengan dukungan keluarga yang tinggi, 93,3\% ikut KB dan 6,7\% tidak ikut KB. Sedangkan pada kelompok responden dengan dukungan keluarga yang rendah $57,9 \%$ tidak ikut KB dan 42,1\% ikut KB. Hal ini berarti bahwa responden dengan dukungan keluarga yang tinggi, maka proporsinya lebih besar untuk mengikuti KB.

Berdasarkan hasil penelitian, diketahui keikutsertaan KB di Desa Argomulyo Sedayu Bantul Yogyakarta tahun 2014 adalah sebesar $67,30 \%$. Persentase tersebut lebih rendah dibandingkan dengan angka pemakaian kontrasepsi rata-rata Kabupaten Bantul yang telah mencapai 81,4\%(3). Belum membudayanya program KB di masyarakat disebabkan antara lain karena kondisi lingkungan sosial, budaya, masyarakat dan keluarga yang masih menganggap KB belum atau tidak penting dilakukan, pengetahuan dan kesadaran PUS dan keluarganya dalam ber-KB masih rendah, keterbatasan penerimaan serta aksesbilitas pelayanan kontrasepsi masih terbatas(1).

Faktor-faktor yang mempengaruhi keikutsertaan KB pada Pasangan Usia Subur (PUS) diantaranya adalah adanya dukungan keluarga(8). Dukungan keluarga mengacu pada suatu dukungan yang dipandang oleh angggota keluarga lain sebagai suatu hal yang dapat bermanfaat baik dalam hal pemecahan masalah, pemberian keamanan dan peningkatan harga diri. Dukungan keluarga merupakan salah satu faktor penguat (reinforcing factor) yang sangat berpengaruh terhadap seseorang untuk berperilaku positif yang akan mempengaruhi perkembangan dan kemajuan program KB di Indonesia(9).

Kemajuan program KB tidak bisa lepas dari adanya dukungan dari keluarga karena hal tersebut berkaitan erat dengan dorongan atau motivasi yang diberikan keluarga terhadap PUS untuk ber-KB. Dukungan keluarga dalam program KB merupakan suatu bentuk dari kepedulian keluarga yang memberikan kontribusi secara nyata untuk mewujudkan keluarga kecil yang berkualitas(1).

Hasil penelitian yang telah dilakukan terhadap populasi Pasangan Usia Subur (PUS) di 6 Dusun yang terletak di Desa Argomulyo Sedayu Bantul Yogyakarta Tahun 2014 menunjukkan bahwa, terdapat hubungan positif yang sangat signifikan antara dukungan keluarga dengan keikutsertaan PUS untuk ber-KB. Dengan demikian, hipotesis penelitian yang menyatakan ada hubungan antara dukungan keluarga dengan keikutsertaan PUS untuk ber-KB dapat diterima kebenarannya.

Berdasarkan hasil uji hipotesis dengan uji chi- square, nilai signifikansi atau $p<0,05(p=0,000)$. Hal ini berarti, semakin tinggi dukungan keluarga yang diperoleh maka semakin tinggi keikutsertaan PUS untuk ber-KB, demikian pula sebaliknya bahwa semakin rendah dukungan keluarga maka semakin rendah pula keikutsertaan PUS untuk ber-KB. Berdasarkan nilai OR yaitu 19,085 berarti responden dengan dukungan keluarga yang tinggi memiliki kemungkinan 19 kali lebih besar untuk ikut KB daripada responden dengan dukungan keluarga yang rendah. Nilai koefisien kontingensi sebesar 0,479 menunjukkan tingkat keeratan hubungan antara dukungan keluarga dengan keikutsertaan PUS untuk ber-KB adalah sedang.

Tinggi rendahnya dukungan keluarga akan berkorelasi dengan tinggi rendahnya keikutsertaan PUS untuk ber-KB. Melalui dukungan keluarga sebagai salah satu bentuk dukungan sosial, PUS menjadi lebih semangat untuk turut ikut serta dalam program KB. Hal ini sesuai dengan pendapat yang dikemukakan yang menyatakan bahwa dukungan sosial akan meningkatkan kesejahteraan psikologis

Tabel 4. Tabulasi Silang dan Hasil Uji Statistik Hubungan antara Dukungan Keluarga dengan Keikutsertaan KB pada PUS di Desa Argomulyo Sedayu Bantul Yogyakarta Tahun 2014

\begin{tabular}{|c|c|c|c|c|c|c|c|c|c|c|c|c|}
\hline \multirow{3}{*}{$\begin{array}{c}\text { Dukungan } \\
\text { Keluarga }\end{array}$} & \multicolumn{4}{|c|}{ Keikutsertaan KB } & \multirow{2}{*}{\multicolumn{2}{|c|}{ Total }} & \multirow{3}{*}{$\chi^{2}$} & \multirow{3}{*}{$p$-value } & \multirow{3}{*}{$\begin{array}{l}\text { Coef. } \\
\text { Cont. }\end{array}$} & \multirow{3}{*}{ OR } & \multicolumn{2}{|c|}{$95 \% \mathrm{Cl}$} \\
\hline & \multicolumn{2}{|c|}{ Ikut KB } & \multicolumn{2}{|c|}{$\begin{array}{c}\text { Tidak lkut } \\
\text { KB }\end{array}$} & & & & & & & Lower & Upper \\
\hline & $f$ & $\%$ & $f$ & $\%$ & $f$ & $\%$ & & & & & & \\
\hline Tinggi & 416 & 93,3 & 30 & 6,7 & 446 & 100,0 & \multirow{3}{*}{269,740} & \multirow{3}{*}{0,000} & \multirow{3}{*}{0,479} & \multirow{3}{*}{19,085} & \multirow{3}{*}{12,614} & \multirow{3}{*}{28,875} \\
\hline Rendah & 194 & 42,1 & 267 & 57,9 & 461 & 100,0 & & & & & & \\
\hline Total & 610 & 67,3 & 297 & 32,7 & 907 & 100,0 & & & & & & \\
\hline
\end{tabular}

Sumber: Data Primer tahun 2014 
(psychological well being) yaitu melalui perasaan memiliki, menumbuhkan semangat dan peningkatan harga diri serta penyediaan sumber atau bantuan yang dibutuhkan(10).

Secara umum dapat dikatakan bahwa dukungan dapat meningkatkan kontrol personal dan perasaan positif. Pendapat lain menjelaskan bahwa dukungan akan membuat individu tersebut merasa yakin dan menyadari bahwa ia tidak seorang diri bertanggung jawab terhadap masalah kesehatan reproduksi. Jika individu memperoleh dorongan dari orang lain terutama keluarga terdekat untuk mengambil tindakan yang positif, maka individu tersebut termotivasi dan cenderung mengembangkan sikap positif terhadap diri sendiri dan lebih menerima serta menghargai dirinya sendiri(6).

Melalui salah satu sumber dukungan sosial dalam hal ini adalah dukungan keluarga yang dapat berupa dorongan atau motivasi akan timbul keyakinan bahwa individu tersebut merasa dicintai dan diperhatikan. Selain itu, menurut Friedman menjelaskan bahwa dukungan keluarga dapat berfungsi untuk membina rasa, sikap dan praktek hidup keluarga yang mampu memberikan dan menerima kasih saying sebagai pola hidup ideal menuju keluarga kecil bahagia sejahtera(11).

UU Kesehatan nomor 23 tahun 1992 pasal 5 menyebutkan, "Setiap orang berkewajiban untuk ikut serta dalam memelihara dan meningkatkan derajat kesehatan perorangan, keluarga dan lingkungan"(6). Dari pasal tersebut jelas bahwa keluarga memiliki peran yang sangat besar dan berkewajiban menciptakan serta memelihara kesehatan dalam upaya meningkatkan tingkat derajat kesehatan yang optimal khususnya terkait masalah kesehatan reproduksi sebagai modal menuju keluarga kecil yang berkualitas.

Keluarga juga dapat memberikan bantuan dalam bentuk informasi. Informasi tersebut dapat membantu individu menemukan alternatif yang tepat bagi penyelesaian masalah yang mungkin saja dihadapinya. Keluarga dapat memberikan dukungan informasi berdasarkan pengalaman, menyampaikan pengetahuan yang diperoleh, ataupun menyediakan sumber informasi seperti bahan-bahan bacaan tentang KB. Terjangkaunya informasi adalah tersedianya informasi-informasi terkait dengan tindakan yang akan diambil oleh seseorang(6).

Dalam kehidupan, seseorang cenderung memerlukan legitimasi dari keluarga, apabila perilaku tersebut bertentangan atau tidak memperoleh dukungan dari keluarga, maka ia akan merasa kurang atau bahkan merasa tidak nyaman(6). Dengan demikian, bahwa semakin tinggi dukungan yang diberikan oleh keluarga maka responden akan merasa semakin mantap untuk ikut ber-KB, karena rasa tidak nyamannya berkurang. Dalam hal ini orang yang merasa memperoleh dukungan secara emosional merasa lega karena diperhatikan, mendapat saran atau kesan yang menyenangkan pada dirinya(11).

Dukungan keluarga yang diterima responden dalam hal ini dukungan yang memberi kontribusi pada keikutsertaan KB berhubungan dengan kualitas dan kuatnya hubungan serta persepsi memiliki orang lain yang dapat dipercaya dan diandalkan untuk memberikan dukungan jika sewaktu-waktu diperlukan(10). Pendapat lain mengemukakan bahwa ikatan keluarga yang kuat sangat membantu ketika keluarga menghadapi masalah, karena anggota keluarga sangat membutuhkan dukungan dan bantuan dari anggota keluarga yang lain(7).

Hasil penelitian ini sejalan dengan penelitian yang dilakukan oleh Wahyuni yang menyimpulkan bahwa partisipasi pria dalam vasektomi dipengaruhi juga oleh dukungan keluarga(12). Astuti, dkk yang menyimpulkan bahwa ada hubungan antara dukungan keluarga dengan penyesuaian diri pada kehamilan pertama(10). Demikian pula dengan penelitian yang dilakukan Musdalifah yang menyimpulkan bahwa dukungan suami (keluarga) berhubungan positif dengan pemilihan alat kontrasepsi hormonal(7).

\section{SIMPULAN DAN SARAN}

Berdasarkan paparan hasil analisis penelitian dan pembahasan yang telah dilakukan dapat disimpulkan sebagai berikut bahwa ada hubungan positif yang signifikan antara dukungan keluarga dengan keikutsertaan KB pada pasangan usia subur (PUS) di Desa Argomulyo Sedayu Bantul Yogyakarta tahun 2014. Persentase keluarga dalam memberikan dukungan/dorongan yang tinggi pada pasangan usia subur (PUS) untuk ber-KB di Desa Argomulyo Sedayu Bantul Yogyakarta Tahun 2014 adalah sebesar 49,2\%. Angka cakupan keikutsertaan KB pada Pasangan Usia Subur (PUS) di Desa Argomulyo Sedayu Bantul Yogyakarta Tahun 2014 adalah sebesar 67,25\%. Saran bagi keluarga agar selalu memberikan dorongan bagi PUS untuk mengikuti KB.

\section{RUJUKAN}

1. BKKBN. Arah Kebijakan dan Strategi BKKBN Tahun 2013. Jakarta: BKKBN; 2012.

2. BKKBN. Istilah dan Pengertian KB. Jakarta: BKKBN; 2009.

3. BPS. Profil Propinsi Daerah Istimewa Yogyakarta Tahun 2010. Badan Pusat Statistika Propinsi DIY. Yogyakarta; 2010. 
4. BKKBN. Program KB Nasional. BKKBN Propinsi DIY. Yogyakarta; 2013.

5. BKKPPKB. Data Hasil Kegiatan Program KB Nasional Kabupaten Bantul. Yogyakarta: BKKPPKB; 2013.

6. Suriyandi. Hubungan Dukungan Keluarga Dengan Kepatuhan Perokok Untuk Tidak Merokok Dalam Rumah Di Desa Gasek Kelurahan Karang Besuki Kota Malang tahun 2011. Universitas Brawijaya Malang; 2011.

7. Musdalifah. Faktor-faktor Yang Berhubungan Dengan Pemilihan Kontrasepsi Hormonal Pasutri di Wilayah Kerja Puskesmas Lampa, Duampanua, Pinrang Tahun 2013. Universitas Hasanudin Makasar; 2013.
8. Hamid, Sirodjudin. Faktor-Faktor Yang Berhubungan Dengan Unmeet Need Keluarga Berencana. Universitas Indonesia; 2002.

9. Noviawati. Panduan Lengkap Pelayanan KB Terkini. Yogyakarta: Nuha Medika; 2011.

10. Astuti, Arini Budi, Singgih Wibowo Santosa dan Muhana Sofiati Utami. Hubungan Antara Dukungan Keluarga Dengan Penyesuaian Diri Perempuan Pada Kehamilan Pertama. Universitas Gadjah Mada; 2010.

11. Friedman M M. Keperawatan Keluarga: Teori dan Praktik. Jakarta: EGC; 1998.

12. Wahyuni. Hubungan Pengetahuan Dan Sikap Akseptor KB Pria Tentang Vasektomi Serta Dukungan Keluarga Dengan Partisipasi Pria Dalam Vasektomi Di Kecamatan Tejakula Kabupaten Buleleng Tahun 2012. Universitas Negeri Surakarta; 2012. 